\title{
Electrodeposition of Ni-Fe-Mo Multilayered Soft Magnetic Films with High Specific Resistance
}

\author{
Osamu SHINOURA
}

Received January 9, 1995 ; Accepted March 15, 1995

\begin{abstract}
Electrodeposition of Ni-Fe-Mo multilayers was investigated. The Ni-Fe-Mo films with excellent soft magnetic properties could be obtained from the tartrate bath. The multilayers consisting of two layers with different molybdenum content were prepared by altemating current density during deposition. The multilayer of $[(100 \mathrm{~nm}-\mathrm{Ni}-\mathrm{Fe}-4 \mathrm{wt} \% \mathrm{Mo} / 20 \mathrm{~nm}-\mathrm{Ni}-\mathrm{Fe}-15 \mathrm{wt} \% \mathrm{Mo}) \times 8]$ had the excellent magnetic properties, with specific resistance of $78 \mu \Omega \mathrm{cm}$ and permeability of 5960 at $10 \mathrm{MHz}$, which was higher than that of the single layer film.
\end{abstract}

\section{INTRODUCTION}

Permalloy ( $\mathrm{Ni}-\mathrm{Fe}$ alloy whose $\mathrm{Ni}$ content is approximately $80 \mathrm{wt} \%$ ) with high permeability, $\mu$, and near zero magnetostriction, $\lambda s$, is one of the best soft magnetic materials for the core of thin film magnetic recording heads ${ }^{1-5)}$. Recently, new soft magnetic films are requested to achieve higher recording density. Many studies have been conducted to find new soft magnetic films with high saturation magnetization to magnetize high coercivity recording media ${ }^{6-9)}$. And also the specific resistance becomes one of the most important properties for soft magnetic films to be able to get a good performance at high frequency use. Molybdenumpermalloy (molybdenum content is approximately 4 wt\%) is known as its excellent soft magnetic properties with high specific resistance ${ }^{10)}$. Electrodeposition of $\mathrm{Ni}$ Mo have been investigated for long time ${ }^{11-14)}$ and $\mathrm{Ni}-\mathrm{Fe}$ Mo films were studies for computer memories in 1950's to 1960 ' $\mathrm{s}^{19}$. On the other hand, multilayers by vacuum deposition were investigated widely to get better magnetic properties ${ }^{16)}$. As for electrodeposited multilayers, $\mathrm{Blum}^{17)}$ reported $\mathrm{Ni} / \mathrm{Cu}$ multilayered films which deposited from separated dual bath and Brenner ${ }^{18)}$

R\&D Center, TDK Corporation (2-15-7, Higashi-

Ohwada, Ichikawa, Chiba 272, Japan)

Key Words: Ni-Fe-Mo, Electrodeposition, Multilayer, Soft magnetic properties reported compositionally modulated $\mathrm{Bi} / \mathrm{Zn}$ films by alternating current density during electrodeposition. Since then, much work has been done on multilayered electrodeposition with various methods ${ }^{19-24)}$.

In this paper, preparation of both single layer and multilayer of Ni-Fe-Mo films, their soft magnetic properties and the analysis of the films are reported.

\section{EXPERIMENTAL}

The basic bath for Ni-Fe-Mo electrodeposition is shown in table 1 . The films approximately $1 \mu \mathrm{m}$ thick were electrodeposited on glass substrates (wafer) metallized with $100 \mathrm{~nm}$ of sputtered permalloy seed layer. A paddle type cell ${ }^{25}$ with an orienting magnetic field of 400 Oe was used. An anode was Ti-Pt alloy. A

Table 1 Basic bath formation and operating conditions of $\mathrm{Ni}-\mathrm{Fe}-\mathrm{Mo}$ films.

\begin{tabular}{ll}
\hline Chemicals & $\begin{array}{l}\text { Concentration } \\
\left(\mathrm{mol} \mathrm{dm}^{-3}\right)\end{array}$ \\
\hline $\mathrm{FeSO}_{4}$ & 0.015 \\
$\mathrm{NiSO}_{4}$ & 1.25 \\
$\mathrm{H}_{3} \mathrm{BO}_{3}$ & 0.4 \\
$\mathrm{NH}_{4} \mathrm{Cl}$ & 0.25 \\
Saccharin & 0.001 \\
Tartrate & $0 \sim 0.5$ \\
$\left(\mathrm{NH}_{4}\right)_{6} \mathrm{Mo}_{7} \mathrm{O}_{24}$ & $0 \sim 0.05$ \\
\hline Bath Temperature & $40{ }^{\circ} \mathrm{C}$ \\
pH & 4.5 \\
\hline
\end{tabular}


cathode consisting of a wafer and an auxiliary deflector was used to obtain uniform deposits ${ }^{26)}$. Samples were annealed at $270^{\circ} \mathrm{C}$ for $1 \mathrm{hr}$ in the magnetic field of $1 \mathrm{kOe}$ directed along the hard axis of the deposited films under vacuum condition to modify anisotropy field, $\mathrm{Hk}^{27.28)}$. Film composition was measured by $\mathrm{X}$-ray fluorescence analysis (XRF) and inductively coupled plasma atomic emission spectrometer (ICP). Saturation magnetization, $\mathrm{Bs}$, and coercivity, $\mathrm{Hc}$, were measured using vibrating sample magnetometer (VSM) and permeability was measured using a figure-eight coil method. Specific resistance was measured using a four prove method. Saturated magnetostriction was estimated by an optical cantilever method. Structural properties were examined with transmission electron microscopes (TEM), Auger electron spectroscopy (AES) and electron spectroscopy for chemical analysis (ESCA). Hydrogen contents in alloys were measured by hydrogen analyzer (up to 1800 ${ }^{\circ} \mathrm{C},+6^{\circ} \mathrm{C} / \mathrm{s}$ ) with electrodeposited film and bulky permalloy alloy ( $\mathrm{Ni}-14 \mathrm{Fe}-5 \mathrm{Mo}-3 \mathrm{Cu}$ : NAKANO PERMALLOY Co., JIS C 2531, PC-N grade). In this paper, composition of the films and the multilayers can be represented as [ $\mathrm{t} 1 \mathrm{~nm}$ thick-(Ni -a wt\% $\mathrm{Fe}-\mathrm{b}$ wt\% Mo) $/ \mathrm{t} 2 \mathrm{~nm}$ thick-(Ni -c wi $\% \mathrm{Fe}-\mathrm{d}$ wt\% Mo) $\times \mathrm{n}$ (repeated $\mathrm{n}$ times)] .

\section{RESULTS AND DISCUSSION}

\section{3-1 Single-layer films}

The Ni-Fe films are electrodeposited from the bath which was based on Wolf's bath ${ }^{299}$, similar to the Watt bath for Ni plating. But, it was impossible to deposit the Ni-Fe-Mo film from the Wolf's type bath with an

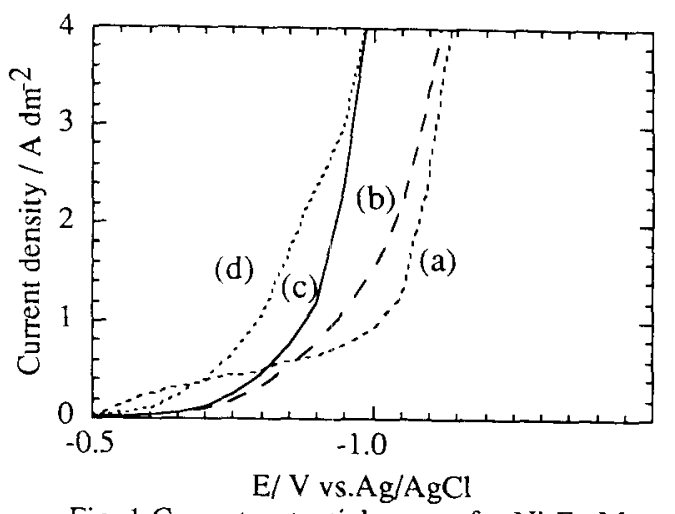

Fig. 1 Current-potential curves for Ni-Fe-Mo $(\mathrm{a}, \mathrm{b}, \mathrm{c})$ and $\mathrm{Ni}-\mathrm{Fe}$ (d) deposition. Concentration in bath $\left(\mathrm{mol} \mathrm{dm}^{3}\right)$ : Tartrate (a) 0 , (b) 0.25 , (c) 0.50

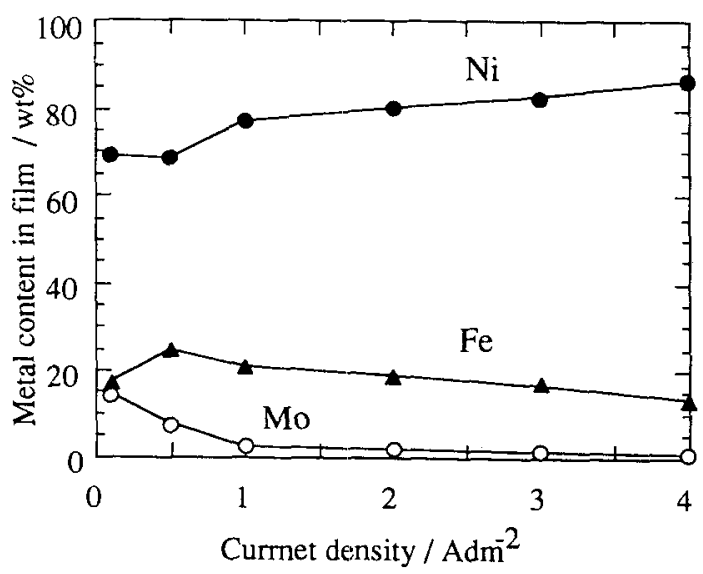

Fig.2 Effects of currrent density on metal content in Ni-Fe-Mo film.

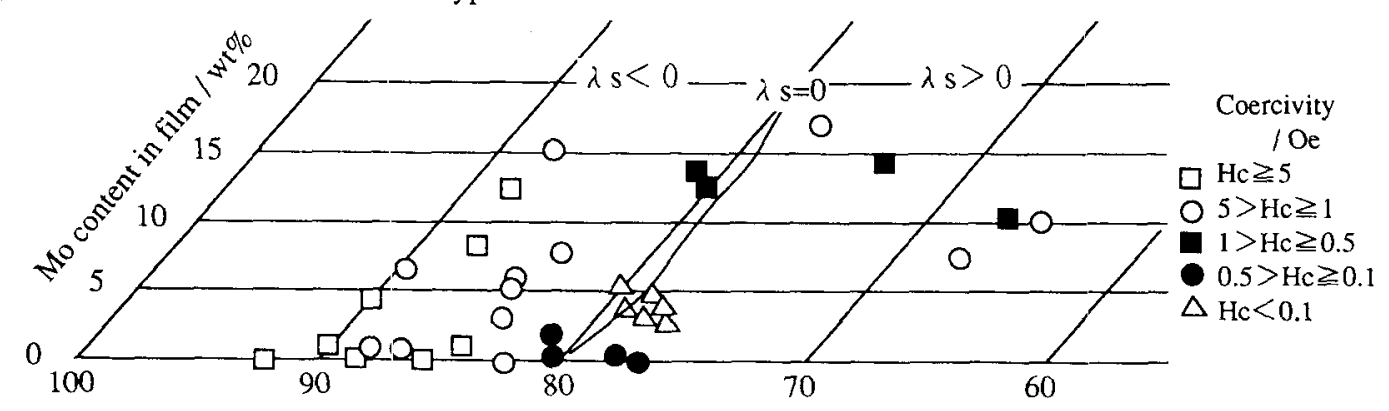

Ni content in film / wt\%

Fig. 3 Effects of composition on coercivity and saturation magnetostriction of electrodeposited $\mathrm{Ni}-\mathrm{Fe}-\mathrm{Mo}$ films. 
ammonium molybdenum. Polarization curves were obtained as shown in Fig. 1, where the deposition of $\mathrm{Ni}$ Fe alloy occurred at about $-0.8 \mathrm{~V}$ (vs. $\mathrm{Ag} / \mathrm{AgCl}$ ). However, an ammonium molybdate shifted deposition potential of alloys to negative side of less than $-1.0 \mathrm{~V}$ (vs. $\mathrm{Ag} / \mathrm{AgCl}$ ) where hydrogen evolution occurred. Tartrate had effect as complexing agent ${ }^{11-13)}$ which shifted the deposition potential of alloys to positive side of -0.9 $\mathrm{V}$ (vs. $\mathrm{Ag} / \mathrm{AgCl}$ ) where alloy films were obtained. The molar ratio of tartrate to metal had to be higher than 0.4 to obtain the films. Composition of the electrodeposited film was affected not only by the metal ion ratio in the bath, but also by the current density. Especially, current density had great influence on molybdenum and nickel content in the film as shown in Fig. 2. At lower current density, the molybdenum content in deposits increased. The molybdenum content could be changed by scale of more than 7 times, $2 \mathrm{wt} \%$ at $4 \mathrm{~A} / \mathrm{dm}^{2}$ to $15 \mathrm{wt} \%$ at $0.3 \mathrm{~A} /$ $\mathrm{dm}^{2}$. Most of the deposited films were bright metallic in appearance without crack. The film deposited at extremely low current densily, i.e., less than $0.2 \mathrm{~A} / \mathrm{dm}^{2}$ was dark in appearance, and it was difficult to obtain thick films because of low current efficiency and large intemal stress. Figure 3 shows the effect of compositions on $\mathrm{Hc}$ and $\lambda$ s of electrodeposited Ni-Fe-Mo films. There were optimum composition for coercivity. The $\mathrm{Ni}-17 \mathrm{Fe}-4 \mathrm{Mo}$ film had the lowest $\mathrm{Hc}$ and near zero $\lambda \mathrm{s}$. The specific resistance of the film increased mainly with an increase in molybdenum content as shown in Fig. 4. The film composed of Ni-Fe-15Mo had specific resistance of $220 \mu \Omega \mathrm{cm}$ which was 10 times higher than that of permalloy film. The Ni-17Fe-4Mo films showed magnetic properties with $0.06 \mathrm{Oe}$ of $\mathrm{Hc}, 0.72 \mathrm{~T}$ of Bs, $40 \mu \Omega \mathrm{cm}$ of specific resistance and 3400 of permeability at $10 \mathrm{MHz}$.

The existences of molybdenum oxide in electrodeposited $\mathrm{Ni}$-Mo films have been discussed with concerning the co-deposition mechanism ${ }^{12-14)}$. The ESCA spectra of molybdenum-3d for the Ni-17Fe-4Mo film is shown in Fig. 5. The binding energy of the peaks are $228.0 \mathrm{eV}$ and $231.2 \mathrm{eV}$ which are determined as metal. The spectra of molybdenum-3d for the Ni-Fe-15Mo film is almost same as Fig. 5. Intensity of oxygen-1s ESCA spectra of the $\mathrm{Ni}-17 \mathrm{Fe}-15 \mathrm{Mo}$ film was very small, but a

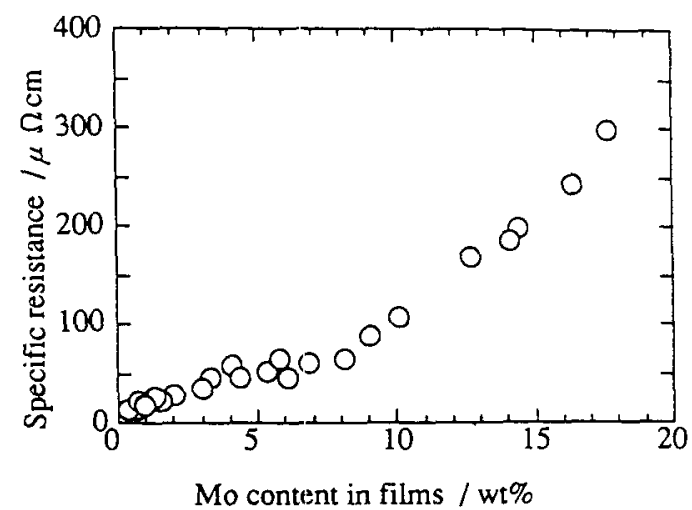

Fig. 4 Effects of Mo content in films on specific resistance of the films.

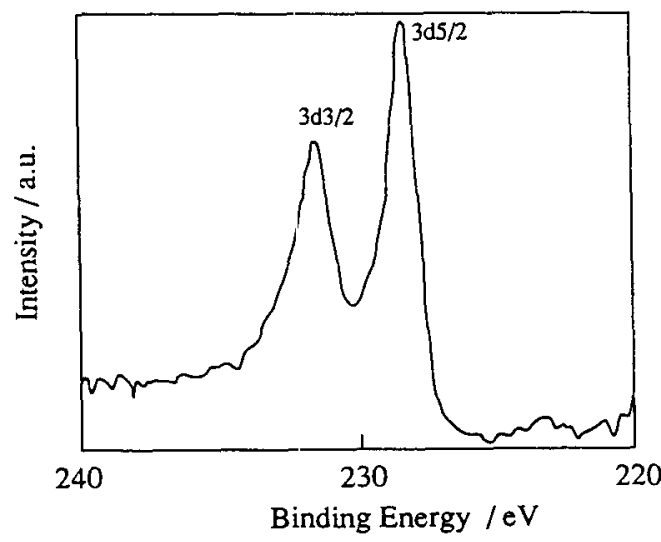

Fig.5 ESCA spectra for electrodeposited Ni-17Fe-4Mo film.

ESCA conditions: $12 \mathrm{kV}-15 \mathrm{~mA}$, SlotM $\mathrm{PE}=40 \mathrm{kV}$

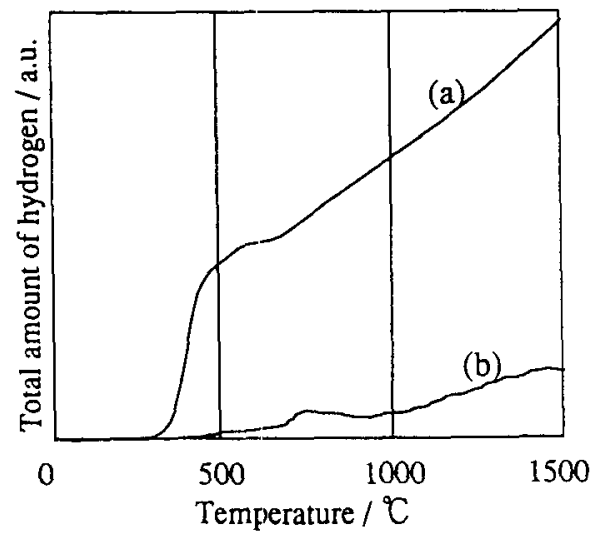

Fig.6 The pattems of hydrogen release during annealing from the Ni-Fe-Mo alloys:

(a) Electrodeposited film, (b) Bulky alloy. 
bit larger than that of the Ni-17Fe-4Mo film. These Ni$\mathrm{Fe}-\mathrm{Mo}$ films are considered to be mainly consisted of metal molybdenum, and a little oxide. The films with higher molybdenum content consisted of more oxide.

The hydrogen content of the electrodeposited $\mathrm{Ni}$ $\mathrm{Fe}-\mathrm{Mo}$ film was $69 \mathrm{ppm}$ and that of bulky $\mathrm{Ni}-\mathrm{Fe}-\mathrm{Mo}$ alloy was $15 \mathrm{ppm}$. The hydrogen in electrodeposited films comes from the cathode sub-reaction and it was released from $300 \mathrm{C}$, and the $40 \%$ of hydrogen was released till $600^{\circ} \mathrm{C}$ as shown in Fig. 6. There was no specified point in releasing curves, so hydrogen in the film was not placed in the specified site in the crystal. The existence of the hydrogen in the films may have relationship with soft magnetic properties which were affected by the crystal structure. Because, the coercivity of the electrodeposited films increased with annealing at more than $350^{\circ} \mathrm{C}$ where hydrogen released. The hydrogen atom, which is very small, in the Ni-Fe films is considered to be placed in the lattice to form the interstitial compound.

\section{3-2 Multilayers}

As mentioned, the specific resistance of $\mathrm{Ni}-17 \mathrm{Fe}$ $4 \mathrm{Mo}$ film is $40 \mu \Omega \mathrm{cm}$, which is twice of the permalloy. Higher specific resistance is desired because the eddy current loss is related to specific resistance. To obtain the film with higher specific resistance, electrodeposition of multilayered $\mathrm{Ni}$-Fe-Mo films was investigated. The basic design was the multilayer which consisted of the main layers of $\mathrm{Ni}-17 \mathrm{Fe}-4 \mathrm{Mo}$ with low coercivity and intermediate layer of $\mathrm{Ni}-17 \mathrm{Fe}-15 \mathrm{Mo}$ with high specific resistance. Multilayers could be obtained by alternating current density during the deposition. At current density of $0.3 \mathrm{~A} / \mathrm{dm}^{2}, \mathrm{Ni}-17 \mathrm{Fe}-15 \mathrm{Mo}$ layers were deposited at rate of $0.7 \mathrm{~nm} / \mathrm{s}$, and at current density of $1.0 \mathrm{~A} / \mathrm{dm}^{2}, \mathrm{Ni}$ $17 \mathrm{Fe}-4 \mathrm{Mo}$ layers were deposited at rate of $3.2 \mathrm{~nm} / \mathrm{s}$. The design of the multilayer is important to get the film desired. For example, multilayer with too thick intermediate layers will show higher specific resistance, but also low Bs and high Hc. From some experiments. the multilayer of [ $100 \mathrm{~nm}-\mathrm{Ni}-\mathrm{Fe}-4 \mathrm{Mo} / 20 \mathrm{~nm}-\mathrm{Ni}-\mathrm{Fe}$ $15 \mathrm{Mo}) \times 8$ ] had the best balanced magnetic properties, with $\mathrm{Hc}$ of $0.08 \mathrm{Oe}, \mathrm{Bs}$ of $0.62 \mathrm{~T}$ and specific resistance of $78 \mu \Omega \mathrm{cm}$. Permeability at $10 \mathrm{MHz}$ was 5960 which
Table 2 Magnetic properties of electrodeposited single layer and multilayer of Ni-Fe-Mo alloys.

\begin{tabular}{cccc}
\hline & & Single layer & Multilayer \\
\hline $\mathrm{Hc}$ & $(\mathrm{Oe})$ & 0.06 & 0.08 \\
$\mathrm{Bs}$ & $(\mathrm{T})$ & 0.72 & 0.62 \\
\hline$\mu(1 \mathrm{MHz})$ & 6700 & 6800 \\
$\mu(5 \mathrm{MHz})$ & 5150 & 6600 \\
$\mu(10 \mathrm{MHz})$ & 3400 & 5960 \\
\hline$\rho(\mu \Omega \mathrm{cm})$ & 40 & 78 \\
\hline
\end{tabular}

Single layer $\quad \mathrm{Ni}-17 \mathrm{Fe}-4 \mathrm{Mo}$
Multilayer $[100 \mathrm{~nm}-(\mathrm{Ni}-17 \mathrm{Fe}-4 \mathrm{Mo})$

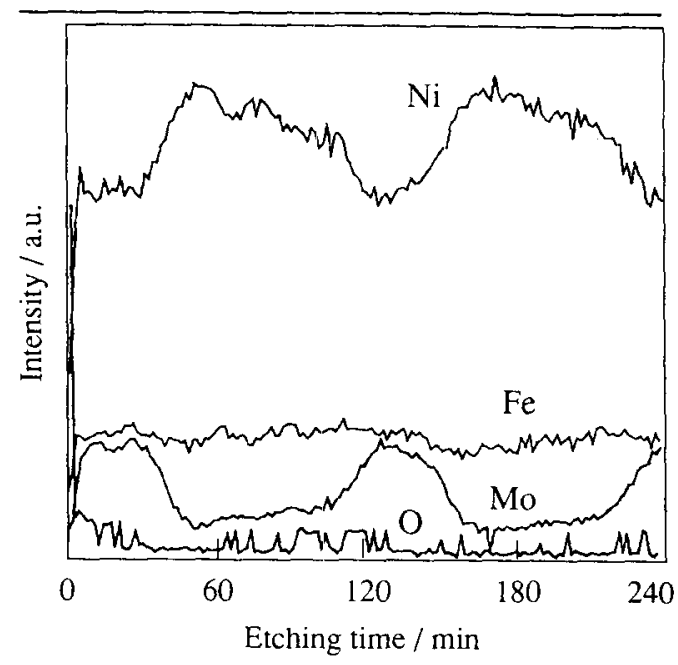

Fig.7 AES depth profiles of electrodeposited multilayer of $[(100 \mathrm{~nm}-\mathrm{Ni}-\mathrm{Fe}-4 \mathrm{Mo} / 20 \mathrm{~nm}-\mathrm{Ni}-\mathrm{Fe}-$ $15 \mathrm{Mo}) \times \mathrm{n}]$.

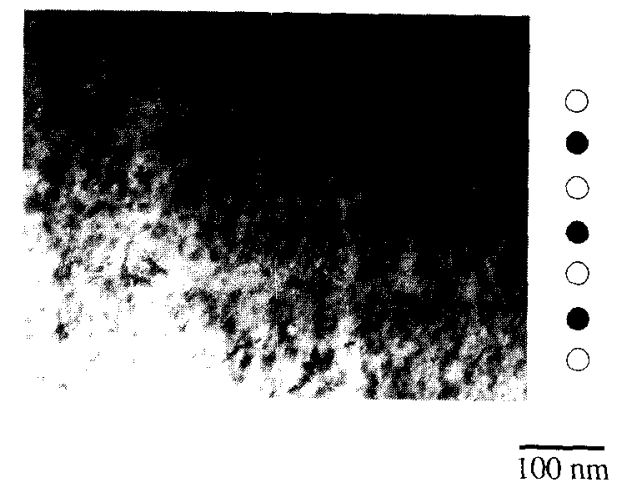

Fig. 8 Cross section TEM picture of multilayer : $[(\mathrm{O}: 100 \mathrm{~nm}-\mathrm{Ni}-\mathrm{Fe}-4 \mathrm{Mo} / \mathrm{O}: 20 \mathrm{~nm}-\mathrm{Ni}-\mathrm{Fe}-$ $15 \mathrm{Mo}) \times \mathrm{n}$ ]. 
was much higher than single layer as shown in Table 2. The intermediate layers acted as spacers to magnetostatically couple magnetic layers ${ }^{16,30)}$. The multilayers with high specific resistance and with coupled soft magnetic layers could show such high permeability at high frequency. From simple calculation with designed data, specific resistance of the multilayer was $47 \mu \Omega \mathrm{cm}$, which was lower than the experimented data. It was due to an error of composition of the intermediate layers because the electrodeposition at lower current density was not so stable. The molybdenum content of the intermediate layers might be a bit higher than that of single layers and there are diffused layers between the main layers and intermediate layers. Also surface roughness of each layers may have great effects on resistivity.

Auger spectroscopy was used to determine the compositional modulation with the multilayer. The estimated etching rate was $1 \mathrm{~nm} / \mathrm{min}$. Figure 7 showed the outer four layers of the multilayer that outer layer of $20 \mathrm{~nm}$ was composed of Ni-Fe-Mo alloys with higher molybdenum content than inter layer of $100 \mathrm{~nm}$. The thickness ratio of the modulation measured from AES was about 5:1 which was same as designed layers thickness of $100 \mathrm{~nm} / 20 \mathrm{~nm}$. Oxygen was observed only at near surface. The iron content did not show the compositionally modulation because there was little influence of current density on iron content in the films as shown in Fig. 2. Figure 8 shows cross-sectional TEM image of multilayer with the [(100 nm-Ni-17Fe-4Mo / $20 \mathrm{~nm}-\mathrm{Ni}-17 \mathrm{Fe}-15 \mathrm{Mo}) \times \mathrm{n}]$. The multilayered structure can not be observed so clearly. There are glimmering lateral stripes, the main layers $(\bigcirc$ ) with fine particles and the intermediate layers ( ) with no particle images. Molybdenum in Ni-Fe-Mo film had effect to decrease the particle size.

\section{CONCLUSION}

Electrodeposition of $\mathrm{Ni}-\mathrm{Fe}-\mathrm{Mo}$ alloy was investigated. The molybdenum ion in $\mathrm{Ni}-\mathrm{Fe}$ bath shifted the deposition potential of alloys to negative side and the tartrate shifted the potential to positive side to be able to obtain films. The $\mathrm{Ni}-17 \mathrm{Fe}-4 \mathrm{Mo}$ film had low coercivity of $0.06 \mathrm{Oe}$ and $\mathrm{Ni}-17 \mathrm{Fe}-15 \mathrm{Mo}$ film showed very high specific resistance of $220 \mu \Omega \mathrm{cm}$. Electrodeposited films consisted of much hydrogen than the bulk sample and it was considered to have effect on soft magnetic properties. The molybdenum content in the deposited films was effected by current density and it has great influence on specific resistance of the films. Applying this phenomenon, multilayered Ni-Fe-Mo films were obtained by alternating current density during deposition. The multilayers which consisted of the thick layers with low coercivity and the thin intermediate layers with high specific resistance, showed high permeability with high specific resistance. Specific resistance of the multilayers may be effected by the interdiffused layers and the surface roughness of each layers.

The author wishes to thank Dr. S. Saito, director of TDK Corp., for his support in this research and A. Kamijima, Y. Kagaya, K. Yanagiuchi and H. Chihara for their valuable assistance.

\section{REFERENCES}

1)D.P.Gregg, US Patent, 3344237 (1967).

2)L.T.Romankiw, I.M.Croll and M.Hatzakis, IEEE Trans Magn., MAG-6, 597 (1970).

3)J.P.Lazzari and I. Melnick, IEEE Trans.Magn., MAG-6, 601 (1970).

4)R.I.Potter, R.J.Schmulian and K.Hartman, IEEE Trans.Magn., MAG-7, 689 (1971).

5)M.Hanazono, K.Kawakami, S.Narishige, O.Asai, E.Kaneko, K.Okuda, K.Ono, H.Tsuchiya and W.Hayakawa, IEEE Trans.Magn., MAG-15, 1616 (1979).

6)S.H.Liao, IEEE Trans.Magn., MAG-23, 2981 (1987).

7)Y.Omata, N.Kaminaka, Proc. of the 2nd Symp. on Magnetic Materials, Processees, and Devices, Electrochem.Soc., PV91-2, 575(1991).

8)T.Osaka, T.Hommma, N.Masubuchi, K.Saito, Y.Yamazaki and T.Namikawam, J.Magn.Soc.Jpn., 14,309 (1990).

9)O.Shinoura and A.Kamijima, J.Surface Finishing Soc.Jpn., 44, 1114 (1993).

10)R.M.Bozorth, Ferromagnetism, D.Van Nostrand Company Inc., p136 (1951).

11)H.J.Seim and M.L.Holt, J.Electrochem.Soc., 96, 205 
(1949).

12)D.W.Emst, R.F.Amlie and M.L.Holt, J.Electrochem. Soc., 102, 461(1955).

13)D.W.Emst and M.L.Holt, J.Electrochem.Soc., 105 , 686 (1958).

14) S.Rengakuji, Y.Nakamura, M.Inoue, K.Nishibe, and H.Imanaga, Denki Kagaku, 59, 885 (1991).

15)W.O.Freitag and J.S.Mathias, J.Electrocham.Soc, 112, 64(1965).

16) H.Clow, Nature, 194, 1035 (1962).

17)W.Blum, Trans. Am. Electrochem. Soc., 40, 307 (1921).

18)Brenner, Electrodeposition of Alloys, Volume $\square$, Academic Press, p589 (1963).

19) J.Mriveriro and G.Rivero, IEEE Trans.Magn., MAG-17, 3082 (1981).

20)J.Yahalom and O.Zadok, J.Mat.Sci., 22,49(1987).

21)D.S.Lashmore and M.P.Dariel, J.Electrochem.Soc., 135, 1218 (1988).

22)L.T.Romankiw and J.D.Olsen, Proc. of the Sym.on
Magnetic Materials, Processes, and Devices, Electrochem. Soc., PV.90, 339 (1990).

$23)$ K. Lon, J.W.Chang, P.C.Andricacos and L.T.Romankiw, Extended Abstracts of ECS, Vol.912, 594 (1991).

24)M.Alper, K.Attenborough, R.Hart, S.Lane, D.S.Lashmore, C.Younes and W.Schwarzacher, App.Phys.Lettrer, 63, 2144 (1993).

25)L.T.Romankiw, R.E.Acosta and J.V.Powers, Extended Abstracts of ECS, Vol.77-2, 761 (1977).

26)O.Shinoura and F.Kimura, Preprints of 82 nd Meeting, Surface Finishing Soc.,Jpn, 250 (1990).

27) Y.Jitake and Y.Shimada, J.Mag. Soc.Jpn., 15, 361 (1991).

28)T.Osaka, T.Homma, K.Kageyama, Y.Matsunae, Denki Kagaku, 62, 987 (1994).

29) I.W.Wolf, J.Electrochem Soc., 108, 959(1961).

30) J.C Slonczewski, B.Petek and B.E Argyle, IEEE Trans.Magn., 24, 2045(1988). 